\title{
- Informação, interculturalidade e a Covid-19 em territórios indígenas de Mato Grosso do Sul
}

\author{
In(formation), interculturality and the Covid-19 in indigenous \\ territories of Mato Grosso do Sul
}

\author{
Andréia Sangallia, * \\ Neimar Machado de Sousa ${ }^{a}$ (D)
}

\begin{abstract}
RESUMO: A inesperada situação de confinamento social com o intuito de diminuir o contágio entre a população pela COVID 19 impactou diretamente os povos tradicionais Guarani, Kaiowá e Terena e seu Tekohá. Partindo do princípio que a saúde é um modo de ser e viver, que respeita as visões próprias dos povos indígenas em relação ao seu bem-estar, e considerando a precarização a que foram submetidos desde a chegada dos conquistadores europeus, principalmente devido às doenças trazidas e que eram desconhecidas por estes povos, a COVID-19 adentra os territórios indígenas, tornando essencial ações educativas que contribuam para a divulgação de informações compreensíveis a respeito da doença. Nesse contexto, foram elaboradas cartilhas de orientações em saúde que consideraram as cosmologias ameríndias representadas na região de Dourados (MS), pelos povos Guarani, Kaiowá e Terena e que rompem com a reprodução da lógica colonial de que os conhecimentos médicos europeus são superiores aos dos indígenas. A circulação do material impresso ampliou os debates entre a parentela indígena sobre os cuidados fundamentais no enfrentamento à Pandemia e passou a ser utilizado como material pedagógico de apoio aos professores e escolas indígenas locais.
\end{abstract}

Palavras-chave: Saúde indígena; Cosmologia; Educação Escolar Indígena.

ABSTRACT: The unexpected situation of social confinement in order to reduce contagion among the population by COVID 19 directly impacted the traditional Guarani, Kaiowá and Terena and their Tekohá. Assuming that health is a way of being and living, that it respects indigenous peoples' own views on their well-being, and considering the precariousness to which they have been subjected since the arrival of european conquerors, mainly due to the diseases brought and unknown by these peoples, COVID-19 enters the indigenous territories, making educational actions essential to contribute to the dissemination of comprehensible information about the disease. In this context, booklets of health guidelines were elaborated and these booklets considered the amerindian cosmologies represented in the region of Dourados (MS), by the Guarani peoples, Kaiowá and Terena break with the reproduction of the colonial logic that european medical knowledge is superior to that of indigenous people. The circulation of printed material expanded the debates among the indigenous kinship about the fundamental care in the fight against the Pandemic and began to be used as pedagogical material to support local indigenous teachers and schools.

Keywords: Indigenous Health; Cosmology; Indigenous School Education.

\footnotetext{
a Programa de Pós-Graduação em Educação e Territorialidade, Faculdade Intercultural Indígena, Universidade Federal da Grande Dourados, Dourados, Mato Grosso do Sul, Brasil.

*Correspondência para/Correspondence to: Andréia Sangalli. E-mail: andreisangalli@ufgd.edu.br. Endereço institucional: Faculdade Intercultural Indígena, Universidade Federal da Grande Dourados, Dourados, Mato Grosso do Sul, Brasil.
}

Recebido em/Received: 15/08/2020; Aprovado em/Approved: 04/11/2020.

Artigo publicado em acesso aberto sob licença CC BY 4.0 Internacional $@(i)$ 


\title{
INTRODUÇÃO
}

Endemias, epidemias e pandemias impactam a humanidade desde o início de sua existência. O caráter distintivo entre elas está em sua manifestação coletiva e singular; coletiva enquanto fenômeno que atinge grupos de indivíduos provocando alterações no modo de andar a vida e singular enquanto ocorrência única na unidade de tempo e espaço em que ocorre (BARATA, 1987).

Epidemia representa a ocorrência de um agravo acima da média (ou mediana) histórica de sua ocorrência. $O$ agravo causador de uma epidemia tem geralmente aparecimento súbito e se propaga por determinado período de tempo em determinada área geográfica, acometendo frequentemente elevado número de pessoas. Quando uma epidemia atinge vários países de diferentes continentes, passa a ser denominada pandemia (MOURA, 2012, p.15).

A pandemia (do grego, pan- todo, e demos- povo) tem como fatores determinantes e condicionantes diversas situações econômicas, culturais, ecológicas, psicossociais e biológicos. Para a epidemiologia (área que estuda como doenças afetam populações humanas), a pandemia é uma epidemia que se origina em um ponto específico do globo e se propaga através dos continentes ao longo do tempo (JARDIM, 2020).

Diferentes agentes, como protozoários, vírus e bactérias, são os responsáveis pelas endemias, epidemias e pandemias mais relevantes em todo o mundo. As formas de transmissão desses agentes infecciosos variam, podendo ocorrer por meio do contato respiratório, de forma direta, por fômites (objetos ou partículas contaminadas), por transmissão vetorial (mosquitos e carrapatos) ou por meio de fezes contaminadas (MOURA, 2012, p.8).

No século XX, ocorreram vários episódios de pandemias causadas por vírus que ganharam, mediante mutações, a capacidade de infectarem seres humanos. Isto aconteceu com a chamada Gripe Espanhola em 1918, que se espalhou a partir do Texas (EUA), onde um destes vírus adquiriu a capacidade de infectar seres humanos.

\begin{abstract}
...a história do vírus influenza de 1918 não é simplesmente o caos, a morte e a desolação da sociedade em uma guerra contra a natureza sobreposta a uma guerra contra outra sociedade humana... A pandemia de gripe que eclodiu em 1918 foi o primeiro grande choque entre a natureza e a ciência moderna. Foi o primeiro grande choque entre uma força natural e uma sociedade com indivíduos que se recusavam a se submeter a essa força ou a simplesmente implorar por salvação através da intervenção divina, indivíduos determinados a confrontar essa força diretamente, com uma tecnologia em desenvolvimento e suas mentes (BARRY, 1947, p.1314).
\end{abstract}

Os vírus estão entre os primeiros seres da terra, mas não são seres vivos como nós, pois precisam infectar as células de outros seres para replicarem. Em termos de evolução, podemos reconhecer vírus muito antigos, como o grupo herpes e que se adaptaram a mamíferos há dezenas de milhões de anos, com uma grande capacidade de se manter de forma latente nos hospedeiros, inclusive no homem (SCHATZMAYR e CABRAL, 2012, p.167). Possuindo dezenas de sistemas diferentes de replicação no interior das células e também diferentes formas de transmissão de um hospedeiro a outro, além de sofisticadas estratégias de sobrevivência, os vírus foram qualificados como seres "inteligentes, subversivos, sutis e engenhosos" (CRAWFORD, 2000 apud SCHATZMAYR e CABRAL, 2012, p.16). 
Vírus mais recentes são responsáveis por epidemias como o sarampo e de pandemias, como é o caso da influenza; uma das explicações atribuídas a propagação e poder infectante dos vírus na espécie humana está na criação de núcleos de agricultura pelo homem, bem como pela domesticação de animais e adoção de formas mais sedentárias de vida. Os aglomerados humanos e a criação intensiva de animais domésticos e plantas em pequenos espaços, facilita a rápida disseminação destes agentes, sendo um problema de crescente importância dentro de nossa atual sociedade (SCHATZMAYR e CABRAL, 2012, p.167).

A disseminação de epidemias entre os seres humanos é inevitável pois nosso sistema econômico baseia-se na preposição da possibilidade de crescimento exponencial e infinito, e sua base moderna e cartesiana, classifica os demais entes naturais como coisas inanimadas. Esse modelo tem promovido a ocupação acelerada de áreas florestais por desmatamentos a fim de ampliar os sistemas agrícolas de monoculturas, "favorecendo as condições propícias para que a vida selvagem se aproxime dos agrupamentos humanos" (ALBUQUERQUE et al., 2020). Outros fatores, como a criação de animais no sistema de confinamento e a aglomeração cada vez maior de pessoas em grandes centros, corroboram para a proliferação exponencial destes micro-organismos e facilitam o contágio.

Essa condição de confinamento forçado é uma realidade entre os povos indígenas, que constituam parte da população sul mato-grossense e que foram suprimidos a reservas superpopulosas e casas (barracos) de um cômodo, como observado na Reserva Indígena de Dourados (RID), Mato Grosso do Sul, sendo essa uma variável que aumenta o risco de doenças infecciosas e torna impossível o distanciamento social. A condição de confinamento associada à falta d'água e de saneamento básico, resulta em espaço ideal para a disseminação de doenças contagiosas, como as doenças virais.

O perfil epidemiológico dos povos indígenas no Brasil é, portanto, bastante complexo. As doenças infecciosas e parasitárias permanecem como importante causa de morbimortalidade. Ao mesmo tempo, vem ocorrendo um variado processo de transição, no qual novos agravos passam a exercer forte pressão sobre os perfis de adoecimento e morte preexistentes. É o caso das doenças crônicas não transmissíveis, dos transtornos mentais e comportamentais e das causas externas de adoecimento e morte (BRASIL, 2018).

Nesse complexo cenário, a ocorrência das mais diversas doenças e problemas de saúde se agrava entre os grupos sociais que estejam vivendo em situações socialmente desfavoráveis, ou seja, entre os mais pobres, entre grupos étnicos minoritários ou grupos que sofrem qualquer tipo de discriminação (BARRETO, 2017, p.2100). Torna-se então imprescindível atentar para o comportamento desta pandemia nas distintas regiões, adaptando estratégias de enfrentamento desta emergência global e suas repercussões em nível local.

Os Coronavírus causam infecções respiratórias e intestinais em humanos e animais; sendo que a maioria das infecções por esses micro-organismos em humanos são causadas por espécies de baixa patogenicidade, levando ao desenvolvimento de sintomas do resfriado comum, no entanto, podem eventualmente levar a infecções graves em grupos de risco, idosos e crianças. Mas acerca da infecção humana pelo novo Coronavírus (2019-nCoV), o espectro clínico não está descrito completamente bem como não se sabe o padrão de letalidade, mortalidade, infectividade e transmissibilidade. Ainda não há vacina ou medicamentos específicos disponíveis e, atualmente, o tratamento é de suporte e inespecífico (BRASIL, 2020). 
A inexistência de medicamentos para a cura da doença tem mobilizado as secretarias estaduais de saúde junto às sociedades médica e farmacêutica na busca de alternativas que possibilitem a diminuição dos sintomas/efeitos da doença e de sua evolução para quadros de infecção mais graves. Em Mato Grosso do Sul, até o meados de maio havia um controle efetivo do número de infectados, mas a flexibilização de algumas atividades associada a falta de conscientização pela população sobre a manutenção das práticas de combate a COVID 19 (isolamento, uso de máscaras, higienização das mãos) resultaram em um grande salto em número de casos principalmente no município de Dourados, em que está localizada a maior aldeia indígena Guarani e Kaiowá do país, além de Dourados ser o maior polo de atendimento em saúde do Cone Sul' de MS.

O objetivo do presente artigo é relatar os impactos da COVID-19 entre os povos tradicionais Guarani, Kaiowá e Terena e seu Tekohá, na região do Conesul de Mato Grosso do Sul, e apresentar uma ação realizada por uma equipe interdisciplinar e intercultural com o intuito ampliar as informações sobre a doença entre esses povos.

\section{OS INDÍGENAS EM MS E A INCIDÊNCIA DA COVID-19}

Mato Grosso do Sul abriga a segunda maior população indígena do Brasil, estimada em 77.025 pessoas, das quais 73.295 mil vivem em terras indígenas (IBGE, 2012). No que tange à política de gestão e financiamento da educação escolar indígena, foram criados por meio do Decreto ${ }^{\circ} 6.861$, de 27 de maio de 2009, os Territórios Etnoeducacionais (TEEs), espaços sociogeográficos que visam clarificar as relações intersocietárias construídas no processo histórico de lutas e de reafirmação identitárias dos povos indígenas para a garantia de seus territórios, bem como desenvolver políticas específicas nas áreas de saúde, educação e etnodesenvolvimento, na perspectiva de cooperação entre os entes pertencentes aos sistemas federal, estadual e municipais de ensino. Assim, houve a criação de dois Territórios Etnoeducacionais no estado de MS sendo: TEE Cone Sul, ao qual estão diretamente ligadas as etnias Guarani e Kaiowá, e TEE Povos do Pantanal, com as etnias Atikum, Guató, Kadiwéu, Kinikinau, Ofaié e Terena (CEE/MS, 2015, p.2).

Relacionado ao atendimento à saúde indígena, Mato Grosso do Sul tem, atualmente, os Distritos Sanitários Especial Indígenas (DSEI) com 15 Polos Base, 30 Unidades Básicas de Saúde Indígena e 3 Casas de Apoio à Saúde do Índio (CASAI) nos municípios de Amambaí, Campo Grande e Dourados (DSEI/MS 2017). A implantação e funcionamento dos Distritos Sanitários Especiais Indígenas (DSEI) foi oficializada através da Portaria N. ${ }^{\circ} 1163 / G M$, de 14 de setembro de 1999 (MINISTÉRIO DA SAÚDE, 1999), e dentre as suas atribuições estão: facilitar o acesso dos povos indígenas às ações e serviços básicos de saúde, garantir a referência para a atenção à saúde de média e alta complexidade na rede de serviços já existentes, sob gestão do estado ou município; e garantir a participação dos povos indígenas nas instâncias de controle social formalizados em nível dos DSEl, por meio dos Conselhos Locais e Distritais de Saúde (BRASIL 2002, p.38).

As definições das funções exercidas pela Casa de Saúde Indígena estão na Portaria 1.801 de 09/11/2015, sendo, dentre elas de apoiar, acolher e dar assistência aos indígenas referenciados à Rede de Serviços do SUS, para realização de ações complementares

${ }^{1}$ Cone Sul de MS- O Território da Cidadania Cone Sul - MS está localizado na região Centro-Oeste e é composto por 8 municípios: Eldorado, Iguatemi, Itaquiraí, Japorã, Mundo Novo, Naviraí, Sete Quedas e Tacuru (Perfil Territorial, 2015). 
da atenção básica e de atenção especializada, estendendo essa atenção aos acompanhantes, quando necessário (MINISTÉRIO DA SAÚDE/SESAI, 2017).

No tocante ao município de Dourados, que concentra área indígena (Aldeias Jaguapiru e Bororó) mais populosa do país, a maior preocupação em relação à pandemia tem sido com a população indígena.

Atualmente, há mais de 18 mil indígenas das Etnias Kaiowá, Guarani e Terena vivendo confinadas em situações inadequadas para seguir as recomendações sanitárias das autoridades sanitárias. A primeira aldeia no interior da RID, a Bororó, é reconhecida como dirigida pelos Kaiowá, e a segunda, a Jaguapiru, é reconhecida como aldeia dirigida pelos Terena. Os Guarani vivem nas duas aldeias, embora estejam mais concentrados na Jaguapiru (PEREIRA, 2015, p. 788).

Nessas populações as marcas das desigualdades e do isolamento se expressam na dificuldade de acesso aos cuidados de atenção primária em saúde, a falta de profissionais de saúde para atendimento in locu, e a própria estrutura atual das Unidades Básicas de Saúde, que perecem por não suprirem as demandas da população muito antes dos tempos de pandemia.

As vulnerabilidades sociais e demográficas nestas aldeias indicam um alto risco para infecção e complicações por Coronavírus. Nas aldeias de Dourados há um grande número de pessoas indocumentadas vivendo em áreas de conflito que não foram reconhecidas pelo Estado brasileiro como indígenas e que em consequência disso não conseguiram cadastrar-se nos programas emergenciais do governo brasileiro para acesso ao chamado corona voucher.

Na RID, muitos são os desafios para produzir as condições de existência material de modo a atender satisfatoriamente as necessidades biológicas e culturais. O principal desses desafios é ampliar e assegurar o acesso regular e permanente a alimentos de qualidade, em quantidade suficiente para nutrir e manter a saúde da população. Com a destruição das matas, as atividades de caça, pesca e coleta perderam sua importância no provimento de alimentos, e mesmo o cultivo de roças de coivara ou mecanizada tornou-se impossível para a maioria. Cada vez mais se acentua a dependência da compra de alimentos e produtos industrializados. Isso implica a necessidade de salário e renda, pouco disponível na reserva... e a mudança na dieta alimentar criou o problema da carência de proteínas, vitaminas e outros nutrientes, já que a alimentação fornecida é baseada na oferta de energéticos (carboidratos, amidos e açúcares) (PEREIRA, 2015, p. 792).

A falta de estrutura dentro da Reserva Indígena de Dourados e na maioria das aldeias indígenas localizadas em MS obriga seus moradores a se deslocarem para a cidade em busca de atendimento médico, trabalhos temporários, busca de alimentos e coleta de materiais recicláveis, entre outros motivos que impedem o isolamento social. Outra realidade entre os indígenas é que parte dos moradores se alimenta com o que consegue obter no mesmo dia, sendo o isolamento um complicador para os indígenas que dependem da coleta diária de alimentos para suas necessidades nutricionais. Como afirma Santos (2020, p.11),

Esses grupos padecem de uma especial vulnerabilidade que precede a quarentena e se agrava com ela. Tais grupos compõem aquilo a que chamo de Sul. Na minha concepção, o Sul não designa um 
espaço geográfico. Designa um espaço-tempo político, social e cultural.

A falta de água e saneamento básico são outros fatores associados diretamente com o contágio por Coronavírus e outras infecções. Embora a reserva esteja a menos de um quilômetro de distância da cidade de Dourados, cerca de 30\% de seus moradores não tem acesso à água, coleta de lixo e saneamento.

No bojo dos fatores associado ao agravamento dos quadros da COVID-19 e respectivamente no aumento das vulnerabilidades nas aldeias de Dourados estão doenças incidentes entre os indígenas e que comprometem o sistema respiratório, como a tuberculose (ARAÚJO, 2020). A ocorrência de surtos de tuberculose entre os indígenas de Mato Grosso do Sul já é antiga. Os estudos epidemiológicos indicam que as epidemias se alastram mais rapidamente entre os povos indígenas em diferentes regiões do mundo, tendo em vista sua desvantagem econômica e as consequências sociais e em saúde. Apenas no ano de 2011 , havia 80 casos diagnosticados de tuberculose em Dourados e pelo menos uma centena de pessoas com os quais mantinham contato frequente com estes pacientes (SOUSA, 2020).

Essa condição de carência em saúde, além de outras como a nutricional, a educacional e a cultural, contribuem em muitas situações para o aumento de doenças respiratórias como, por exemplo, bronquite, pneumonia, coqueluche e quadros gripais, bem como outras doenças infectocontagiosas como a dengue, a leishmaniose, a malária, H1N1, hepatites, ISTs (infecções sexualmente transmissíveis), além de hipertensão, diabetes, obesidade e anemias.

Relacionado ao cenário atual, este quadro de doença pela COVID-19 é mais preocupante ainda, pois faltam testes rápidos, equipamentos de proteção individual e equipe suficiente para fazer este monitoramento nas unidades de saúde na reserva indígena de Dourados. A reserva indígena de Dourados não é a única área com risco considerado alto para disseminação do Coronavírus. A título de exemplo, menciona-se a situação da Aldeia Bananal, no município de Aquidauana, onde há 30 famílias sem água há um mês e segundo relato de TERENA (2020).

[...] fica impossível se realizar as medidas higiênicas de precaução contra o Coronavírus, já que necessitam do recurso hídrico para lavar as mãos, tomar banho e realizar a limpeza geral. O problema afeta principalmente os idosos que fazem parte do grupo de risco pela baixa imunidade e que enfrentam dificuldades de deslocamento. A responsabilidade neste caso é do Distrito Sanitário Especial Indígena de Mato Grosso do Sul (DSEI-MS), que ainda não conseguiu solucionar o problema.

Em Dourados, os membros do Conselho Local de Saúde, da etnia terena, acrescentam que dentre as variáveis que aumentam o fator de risco à COVID-19 nas aldeias de Dourados estão a falta de habitações adequadas, a deficiência nutricional e a falta de água, resultado do confinamento em pequenas áreas e a dependência do fornecimento de cestas básicas do governo (SOUSA, 2020).

Resta a estas populações, esquecidas e discriminadas ao longo da história do país, esperar por autoridades que se negam a cumprir os direitos reconhecidos na constituição de 1988, e depositar a esperança e a confiança na medicina tradicional para o tratamento das doenças, visto que a medicina do branco está perto de colapsar na região de Dourados, MS, que foi um dos epicentros na fase inicial da pandemia em Mato Grosso do Sul. 
O início do contágio pelo Coronavírus entre a população indígena de MS ocorreu entre os dias 10 e 11 de maio, em que foi identificada uma indígena com os sintomas característicos da COVID-19. No dia 12 de maio, o boletim do Distrito Sanitário Especial Indígena Mato Grosso do Sul (DSEI-MS) apontava outros cinco casos suspeitos, testados pela ação preventiva conhecida como "sentinela". E no dia 13 de maio foi confirmado o primeiro caso entre indígenas do Mato Grosso do Sul (CIMI, 2020). Para apresentar o processo de evolução da COVID-19 entre as populações indígenas de MS os números de casos são apresentados no Quadro 1.

Tabela 1. Boletim sobre a COVID-19 na Unidades Polo Base de Mato Grosso do Sul entre 13 de maio e 12 de agosto de 2020.

\begin{tabular}{|c|c|c|c|c|c|c|}
\hline POLO BASE & $\begin{array}{c}\text { Casos } \\
\text { Suspeitos }\end{array}$ & $\begin{array}{c}\text { Casos } \\
\text { Confirmados }\end{array}$ & Descartados & $\begin{array}{l}\text { Infectados } \\
\text { (atual) }\end{array}$ & $\begin{array}{l}\text { Cura } \\
\text { Clínica }\end{array}$ & Óbitos \\
\hline Amambai & 18 & 3 & 189 & 1 & 2 & 0 \\
\hline Antônio João & 13 & 2 & 8 & 2 & 0 & 0 \\
\hline Aquidauana & 19 & 274 & 331 & 203 & 56 & 15 \\
\hline Bodoquena & 0 & 0 & 0 & 0 & 0 & 0 \\
\hline Bonito & 0 & 0 & 0 & 0 & 0 & 0 \\
\hline Brasilândia & 0 & 0 & 7 & 0 & 0 & 0 \\
\hline Caarapó & 9 & 20 & 193 & 10 & 10 & 0 \\
\hline $\begin{array}{l}\text { Campo } \\
\text { Grande }\end{array}$ & 0 & 0 & 0 & 0 & 0 & 0 \\
\hline Corumbá & 0 & 0 & 0 & 0 & 0 & 0 \\
\hline Dourados & 22 & 222 & 1187 & 12 & 207 & 3 \\
\hline Japorã & 2 & 11 & 35 & 11 & 0 & 0 \\
\hline Miranda & 14 & 128 & 256 & 112 & 12 & 4 \\
\hline Paranhos & 1 & 0 & 8 & 0 & 0 & 0 \\
\hline Sidrolândia & 3 & 107 & 76 & 75 & 26 & 6 \\
\hline Tacuru & 5 & 60 & 137 & 34 & 26 & 0 \\
\hline
\end{tabular}

Fonte: BOLETIM DSEI/MS 2020 (em 12 de agosto de 2020).

Houve aumento significativo de casos confirmados e consequentes registros de mortes a partir da segunda quinzena do mês de julho. Este padrão de interiorização pela COVID-19 ocorreu nos municípios de MS e nas comunidades indígenas do estado, pois o primeiro óbito indígena pela COVID-19 ocorreu na Reserva Indígena de Dourados ( $2^{\mathrm{a}}$ maior cidade do estado) em 19 de julho de 2020 e mesmo sendo essa a área indígena a que registra o maior número de casos confirmados no estado, até 12 de agosto o número de óbitos manteve-se em 3, enquanto houve crescimento repentino do contágio em área indígena terena nos municípios interioranos de Aquidauana (15), Sidrolândia (6) e Miranda (4) (Quadro 1).

Ao analisar os dados apresentados no BOLETIM DSEI/MS de 12 de agosto de 2020 por Polo Base em MS, os registros de contágio por Coronavírus entre a população indígena do Estado de Mato Grosso do Sul totalizam 826 indígenas infectados, sendo 69\% são da etnia Terena e 31\% da etnia Guarani/Kaiowá. Em relação aos 28 óbitos registrados, 26 eram indígenas terenas, 1 guarani/kaiowá e 1 kaiowá desaldeado, sendo 19 do gênero masculino e 9 do gênero feminino. 
Embora a Organização Mundial de Saúde (OMS) e o Ministério de Saúde considerem grupos de risco idosos com idade superior a 60 anos, gestantes, puerpéras, crianças e indivíduos portadores de comorbidades (MINISTÉRIO DA SAÚDE/SAPS, 2020), no DSEI/MS os casos de infecção por Coronavírus foram mais elevados entre a faixa etária de 20 a 29 anos de idade (Figura 1), entretanto a taxa de letalidade por COVID-19 foi superior a partir de 70 anos de idade (46,4\%).

$\mathrm{Na}$ atual situação, em consonância às condições de baixas temperaturas das estações de outono e inverso no estado, é fulcral que as comunidades indígenas sejam auxiliadas por diferentes frentes de ação que possibilitem a distribuição de alimentos, EPIs (máscaras), produtos de higiene pessoal, roupas de inverno, bem como materiais de informação, para que ampliem os cuidados e busquem a ajuda de profissionais de saúde caso haja suspeita de infecção por COVID-19 ou por outras doenças respiratórias que os acometam nesse período.

\section{Figura 1. Registros de casos de Infecção por Coronavírus e óbitos por COVID-19 no DSEI/MS (de 13 de maio a 12 de agosto de 2020).}

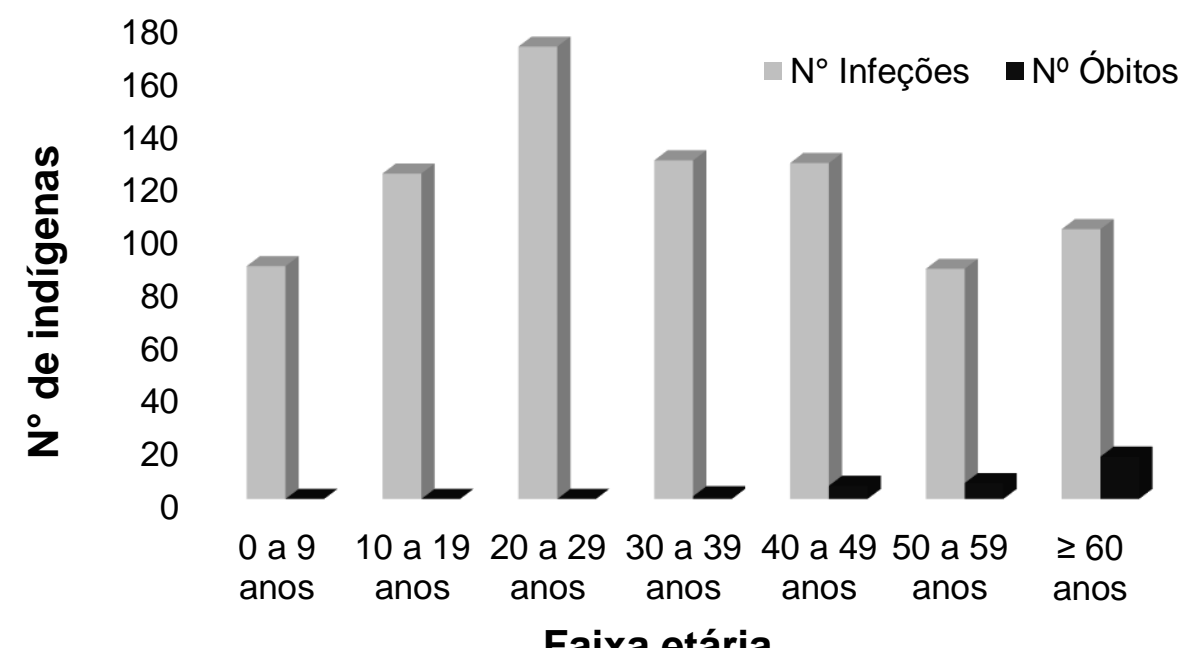

Fonte: BOLETIM DSEI MS 12 de agosto 2020 (BOLETIM DSEI/MS, 2020).

\section{AÇÕES DE INFORMAÇÃO NO COMBATE A PANDEMIA}

No auge da disseminação do vírus em território brasileiro, e com a orientação do Ministério da saúde para o isolamento social na tentativa de postergar o contágio da população, aumentou a preocupação com as comunidades tradicionais, em função das diversas carências já enfrentadas por essas populações quanto às condições básicas de qualidade de vida: acesso à água, a alimentação, a tratamentos de saúde e manutenção das tradições culturais.

Sem a possibilidade de reuniões presenciais em grupos e no ímpeto de propor estratégias colaborativas no combate ao vírus, uma das primeiras ações teve como foco levar informações sobre algo desconhecido a todos e, principalmente, às comunidades indígenas.

A preocupação da disseminação do vírus entre os povos indígenas despertou as instituições de ensino e movimentos sociais de apoio aos indígenas da necessidade de 
ações de conscientização e esclarecimento sobre a síndrome causada pelo Coronavírus em uma linguagem adequada e adaptada à compreensão dos povos tradicionais.

Para que as ações alcançassem seus objetivos, a primeira etapa foi reunir um grupo intercultural via WhatsApp, com o objetivo de elaborar materiais orientadores adaptados à língua materna e às realidades das comunidades indígenas do Cone sul de Mato Grosso do Sul. Além de docentes da Faculdade Intercultural Indígena (FAIND), da Universidade Federal da Grande Dourados (UFGD), o grupo teve a participação efetiva de indígenas, professores de educação básica e profissionais em saúde das etnias guarani, kaiowá e terena, e de estudantes indígenas de Programas de Pós-Graduação que possibilitou delinear de forma mais assertiva os passos para a elaboração dos materiais informativos.

Inicialmente as produções geradas em formato digital seriam veiculadas nas redes sociais, mas com o engajamento da equipe, houve a submissão dos projetos objetivando as publicações para editais de financiamento de materiais impressos. Através do Edital COE № 01, de 30 de março de 2020 - Chamada de propostas de projetos e ações de ensino, pesquisa, inovação e extensão para o combate da COVID19, lançado pela UFGD, foi possível a impressão dos materiais elaborados colaborativamente pela equipe. Foram impressos 500 exemplares neste edital e dez mil exemplares com o apoio de Secretaria Estadual de Saúde de Mato Grosso do Sul.

O primeiro material proposto foi orientado à comunidade geral, mas na língua Kaiowá. Consistiu em uma cartilha contendo informações sobre o vírus e os cuidados básicos necessários a evitar o contágio pela COVID 19 (Figura 2-a e b). O material nominado "Koronavíru" foi elaborado por um coletivo constituído de educadores indígenas e não indígenas, desde os textos na linguagem tradicional até as ilustrações. Por essa razão foram propostas duas versões, observando as singularidades das línguas e traços Kaiowá ( $1^{\text {a }}$ versão- nominada Koronavíru COVID 19) e Terena ( $2^{\circ}$ versão- Koronâviru).

Figura 2. Cartilhas elaboradas coletivamente- a) na língua Kaiowá; b) língua Terena.
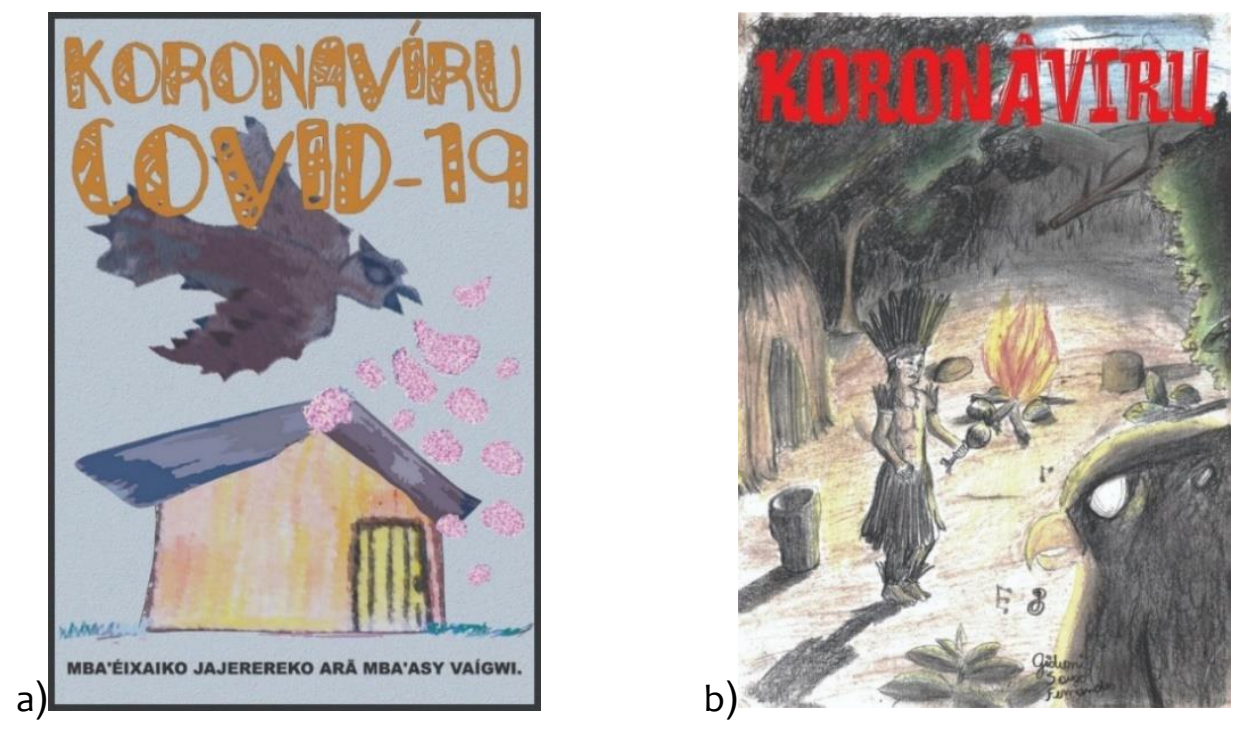

Pensando em uma linguagem mais atrativa às crianças e adolescentes, o material proposto foi um gibi ilustrado intitulado "ARAMI OMOSE KORONAVÍRU" (Figura 3-a e b). A elaboração do texto e das ilustrações foi realizada por um coletivo de educadores indígenas e não indígenas. No gibi, o Coronavírus figura como um viajante que vai transitando e espalhando à doença - COVID 19 - por onde passa. E entre o diálogo de 
Arami e Koronavíru, vão sendo destacados pontos importantes tais como: o que é um vírus; os sintomas a partir da infecção pelo vírus; como é possível diminuir os riscos de contágio; sempre utilizando uma linguagem simples e acessível às crianças e adolescentes indígenas. Para ampliar a mensagem de ARAMI, o gibi também foi proposto na língua portuguesa.

Ao considerar as especificidades das etnias indígenas, cuja a língua principal não é o português, propor materiais informativos que respeitem a linguagem e os seus significados é essencial para que a mensagem transmitida seja compreendida e atue sobre a dimensão social da consciência. "Isso significa que a consciência humana não é só um fenômeno biológico, mas também um fenômeno social” (HAVERROTH, 2009).

Por essas razões, as informações fornecidas no material têm uma organização linguística e simbólica que permita os indígenas reconhecerem a dimensão dos impactos gerados pelo Coronavírus e a necessária adoção de práticas para evitar o contágio e adoecimento da população indígena, fortalecendo e reavivando as práticas tradicionais de rezas, cantos e curas.

\section{Figura 3. Gibis elaborados coletivamente- a) na língua Kaiowá; b) língua portuguesa.}

a)

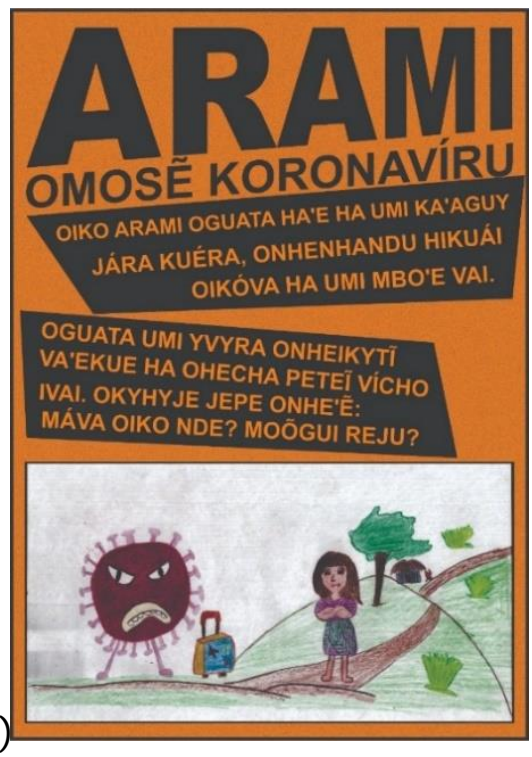

b)

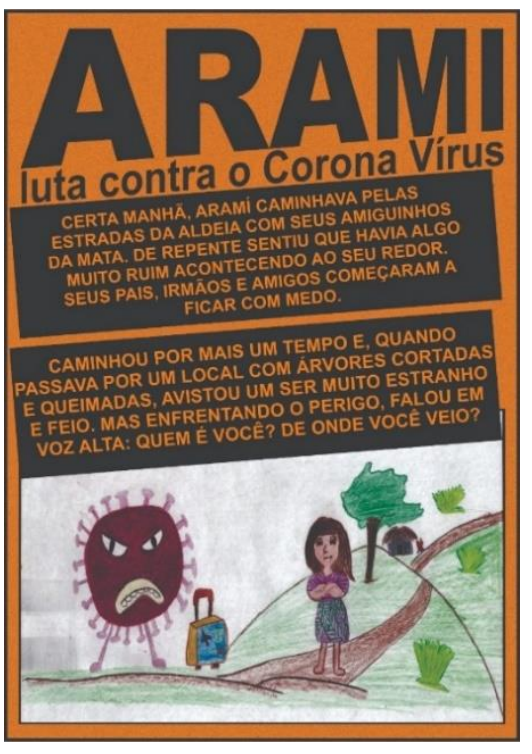

Os materiais produzidos transportam saberes indígenas em suas línguas, sendo esse o veículo mais adequado para sua difusão. Aos não indígenas é necessário questionar-se: Estamos preparados para dialogar com os indígenas sem apequenar o mundo e uniformizá-lo com nossa visão de natureza, de mundo e de saúde? Estas cartilhas são um exercício de pesquisa e de ensino a partir de ideia de descolonizar o próprio pensamento, oferecendo aos leitores outras visões que valorizam o caminho da harmonia e da justiça, como dizem os povos indígenas, Teko joja, para manter a saúde e a vida como o maior valor.

Valorizar os sábios indígenas e seus saberes. Isto foi contemplado no conteúdo e nas explicações presentes nas cartilhas, bem como nas ilustrações e nas cores da natureza e do conjunto seres vivos nela representados. Os remédios e terapêuticas indígenas não subestimam ninguém e nada, pois entendem que uma epidemia como esta, causada por um vírus que é um ser tão pequeno, mas que faz parte constante da natureza, afeta a todos nós e desafia as ciências que se tornaram hegemônicas no 
mundo, mas que mostram sua fragilidade, sem dar respostas à sociedade na medida e velocidade necessária.

Paralelo à produção de materiais, diálogos estão sendo realizados pelo grupo para que todos mantenham-se informados quanto às dificuldades enfrentadas pelas comunidades indígenas e possam participar das ações de luta no combate ao vírus e as condições de precariedade que se acentuaram a partir do confinamento. A enfermeira de etnia Kaiowá Indianara Ramires Machado destaca os enfrentamentos das comunidades indígenas localizadas no Conesul de MS, a partir do confinamento:

\begin{abstract}
A SESAI, a APIB e a MÍDIA ÍNDIO têm veiculado peças informativas, inclusive nas línguas indígenas. As aldeias guarani como, por exemplo, Laranjeira Nhanderu, tem realizado rituais de saúde, denominados áryrovai. A dúvida é se estas informações chegam ao interior das aldeias nas casas mais distantes, pela dificuldade de comunicação onde não há sinal de celular. Nas cidades e para os conectados as orientações chegaram. Há, como no geral da população, grande apreensão, pois há disseminação de fake news sobre descontrole da doença e infecção de indígenas, há casos de crianças internadas com sintomas de gripe, além de um trânsito grande e recente de trabalhadores que saem das aldeias e retornam de outros estados dos trabalhos temporários da colheita da maçã (MACHADO, 2020a).
\end{abstract}

E a ausência de políticas públicas que garantam os serviços essenciais, potencializam as consequências da pandemia.

Em termos normais nós já temos essa dificuldade e escassez de políticas públicas que realmente contemple a comunidade na segurança, no saneamento, na educação e na saúde. Diante de uma pandemia isso só gera mais preocupação ainda para nós moradores aqui da comunidade porque sabemos que em algumas casas a água não chega e quando chega é uma vez por semana ou em alguns períodos do dia. É muito difícil estar vivendo uma pandemia diante de uma situação em que a orientação básica é a lavagem de mãos. "Como é que as pessoas vão seguir esses procedimentos se elas nem têm água em casa. Mas de qualquer forma estamos repassando essas recomendações em nossas comunidades, apesar de algumas pessoas não terem condições financeiras para ter acesso a álcool gel e outros gêneros de higiene (MACHADO, 2020b).

Já sobre os conhecimentos tradicionais relacionados aos cuidados com a saúde e das práticas que estão sendo efetivadas:

Os saberes tradicionais sempre estão presentes no dia a dia e práticas das comunidades, além de serem mais acessíveis, viáveis economicamente e as vezes também o único recurso de saúde que muitas famílias dispõem. Há também uma mobilização de conhecimentos terapêuticos tradicionais utilizados pelos povos indígenas e divulgação nas comunidades das plantas e práticas medicinais recomendadas (MACHADO, 2020a).

Outros movimentos realizados para a conscientização e sensibilização das comunidades indígenas do Conesul, tem sido a realização de "Lives" e a gravação de áudios nas línguas Guarani e Terena, abordando as questões essenciais para a compreensão dos cuidados essenciais para evitar a doença e a dissipação do vírus nas comunidades. 


\title{
A REPERCUSSÃO DAS AÇÕES DE INFORMAÇÃO NOS TERRITÓRIOS INDÍGENAS
}

A COVID-19 presentifica as memórias sociais e coletivas de um passado que reduziu a população dos povos indígenas no Brasil, estimada em 1,1 milhão de indígenas em 1500 e com decréscimo para 500 mil em 1940, o que equivalia a $11 \%$ da população total do Brasil (STEWARD,1949 apud PAGLIARO et al., 2005, p.16). Dentre os fatores que contribuíram para a redução estavam os episódios de epidemias por doenças infecciosas e parasitárias e as tensões agravadas pela fome em razão do colapso dos sistemas de subsistência tradicionais (entre os povos que tiveram contato com frentes agrícolas, seguidos dos que se defrontaram com as expansões extrativistas e pastoris) (PAGLIARO et al., 2005, p.17).

O corpo e saúde são construções biológicas e sociais afetadas pela cultura e com a saúde não é diferente. Os povos indígenas também possuem suas epistemologias alternativas, diferentes dos não indígenas, sendo centradas no cosmo, na natureza, além de considerarem o ser humano em sua dimensão plena. Nessa totalidade, as orientações sobre a COVID-19 devem levar em consideração a língua falada por estes povos, o vocabulário usual em suas comunidades e as práticas tradicionais por eles praticadas para manter a própria saúde. Estes foram alguns dos princípios que orientaram a produção dos materiais pelo grupo.

As ações desenvolvidas coletivamente têm contribuído com uma das necessidades que o surto da COVID 19 gerou: a de propagar informações e que essas sejam compreensíveis à comunidade indígena. A circulação do material impresso ampliou os debates entre a parentela indígena sobre os cuidados fundamentais no enfrentamento à Pandemia. O uso de máscaras e a preocupação em dispor e utilizar materiais de higiene pessoal foi um avanço nas comunidades.

\begin{abstract}
A pandemia e a quarentena estão a revelar que são possíveis alternativas, que as sociedades se adaptam a novos modos de viver quando tal é necessário e sentido como correspondendo ao bem comum. Esta situação torna-se propícia a que se pense em alternativas ao modo de viver, de produzir, de consumir e de conviver nestes primeiros anos do século XXI. Na ausência de tais alternativas, não será possível evitar a irrupção de novas pandemias, as quais, aliás, como tudo leva a crer, podem ser ainda mais letais do que a atual (SANTOS, 2020, p.25).
\end{abstract}

Esta ação foi possível porque houve um diálogo permanente com as lideranças indígenas e órgãos responsáveis pela implementação de políticas públicas (SES/MSSecretaria de Estado de saúde de MS; SED/MS- Secretaria de Estado de Educação e Secretaria Municipal de Saúde e de Educação) apontando que a construção de soluções aos problemas sociais depende do engajamento entre instituições e sociedade para que haja entendimento das peculiaridades do cotidiano dos povos indígenas, das características culturais e do simbolismo que reflete o modo de viver de cada comunidade.

Só com uma nova articulação entre os processos políticos e os processos civilizatórios será possível começar a pensar numa sociedade em que humanidade assuma uma posição mais humilde no planeta que habita. Uma humanidade que se habitue a duas ideias básicas: há muito mais vida no planeta do que a vida humana, já que esta representa apenas 0,01\% da vida existente no planeta; a defesa da vida do planeta no seu conjunto é a condição para a continuação da vida da humanidade (SANTOS, 2020, p. 27). 
O destaque de Santos vai de encontro com a compreensão de Tekoha apresentada por Benites (2020), da importância de o ser humano perceber-se não como centro do universo, mas como parte de um todo e da necessidade de responsabilizar-se pela manutenção e equilíbrio desse todo, formado pelos meios bióticos e abióticos, com todas as suas formas de vida e as condições de materialização desses na natureza.

\begin{abstract}
A vida no tekoha busca reviver continuamente os encontros entre múltiplas trajetórias já realizadas. Reproduzindo este passado, ela (a vida vivida no tekoha) dá sentido ao presente e clareza para o caminho do futuro. Os elementos do tekoha, como as florestas, os rios, a casa de reza e a roça, por exemplo, são linhas condutivas que levam ao passado e às dimensões espirituais e, na volta, trazem a memória viva para atualizar e fundamentar as novas relações necessárias, diante da transformação constante da realidade. Nesta dinâmica da mobilidade espacial e espiritual, o conhecimento caracteriza-se como uma particularidade que permite resistir às pressões homogeneizantes do saber de origem ocidental (BENITES, 2020, p. 20).
\end{abstract}

No encontro entre culturas e de formas distintas de encaminhar soluções é que surgem possibilidades de aprendizados, de transformações e essas interações são fundamentais para enfrentamentos de situações difíceis como é o enfrentamento a COVID 19 e do novo modo de vida (com e pós pandemia).

\begin{abstract}
O tekoha, agora na dimensão física, produz uma vida cheia de experiências contínuas com as outras culturas; no caso da cultura da sociedade não indígena, os fundamentos guarani-kaiowá são alterados. Com o encontro entre culturas, inserem-se outras demandas para a vida, que reorientam o próprio teko; o encanto com o modo de ser dos não indígenas foi possível justamente pela produção de uma outra forma de ver o mundo, que molda o pensamento e a subjetividade para se encantar com outras formas de ser (BENITES, 2020, p. 26).
\end{abstract}

Embora a ação tenha surtido efeitos positivos em relação a ampliar as informação sobre a COVID 19 entre a população Guarani, Kaiowá e Terena do MS, intervenções dessa natureza enfrentam desafios e limitações, seja na falta de recursos para reproduzir exemplares em número suficiente para a população do território indígena Cone Sul/MS, bem como a logística de distribuição que está comprometida em função das necessárias barreiras sanitárias instaladas nas entradas principais das aldeias, constituídas pelos próprios indígenas. Assim, a distribuição ficou sob a responsabilidade de alguns agentes indígenas (dos setores de saúde e educação) que estão sobrecarregados de atividades, mas que não envidam esforços para garantir a segurança e a saúde de suas comunidades.

Há que se destacar que nas aldeias de Dourados, as cartilhas e os gibis passaram a ser utilizados por professores das escolas indígenas em atividades pedagógicas remotas, que foram elaboradas, impressas e entregues aos pais dos estudantes junto com os materiais produzidos pela equipe. Essa prática contribuiu enormemente para a divulgação das informações sobre a COVID 19 entre as famílias indígenas, e evidencia a centralidade que as escolas representam nos territórios indígenas. Essa centralidade é traduzida para além das relações educacionais. A escola desenvolve um papel social atendendo como instituição de serviços públicos (auxiliando nas orientações em relação as dúvidas que os pais têm sobre documentos, direitos a serem reivindicados), segurança alimentar (Programa alimentação na escola, entrega de alimentos), práticas em saúde (auxiliando as Unidades de saúde ou exercendo esse papel, quando essas 
inexistem no Tekohá), além de ser espeço de reavivamento das culturas com as famílias indígenas.

\section{CONSIDERAÇÕES FINAIS}

No cenário evidenciado nas aldeias indígenas de Mato Grosso do Sul, é necessário grifar que os diálogos e a vida com a COVID-19 são e serão parte da história, dos indígenas e dos não indígenas, no tempo presente e futuro e nos espaços, quais sejam.

O episódio do Coronavírus esteve e está marcado por promessas do Estado em atender as necessidades básicas dos indígenas, sendo a prioritário, o acesso a água potável. Entretanto, a garantia de ampliação ao acesso a esse bem, que é diretiro de todos, e de equipamentos de proteção individual, distribuídos pela Secretaria Especial de Saúde Indígena, sofreram vetos por ações do poder, indicando que o subsistema de atenção à saúde indígena, anteriormente e durante a epidemia, tem-se mantido anêmico.

Como aponta sabiamente Krenak (2020, p. 9), “[...] o mundo está agora numa suspensão. E não sei se vamos sair dessa experiência da mesma maneira que entramos. É como um anzol nos puxando para a consciência. Um tranco para olharmos o que realmente importa".

Resta então avaliarmos que caminhos tomaremos e fazermos nossas escolhas. Que o tal novo normal possa transformar as fronteiras visíveis e invisíveis da exclusão e da inferioridade no qual os povos indígenas tem sido historicamente submetidos e reconhecidos e respeitados seus territórios, sua ciência, suas culturas e seu Teko joja.

\section{REFERÊNCIAS}

ALBUQUERQUE, U. P. et al. Pequeno manual para lidar com o mundo pós-pandemia da COVID-19. Recife: Instituto Nacional de Ciência e Tecnologia em Etnobiologia, Bioprospecção e Conservação da Natureza. 2020. E-book. Disponível em: https://www.researchgate.net/publication/342276450_PEQUENO_MANUAL_PARA_LI DAR_COM_O_MUNDO_POS-PANDEMIA_DA_COVID-19. Acesso em: 20 maio 2020.

ARAÚJO, V. Tuberculose deixa índios mais vulneráveis a Covid-19 em Dourados. $O$ Progresso Digital, Dourados, 24 abr. 2020. Disponível em:

https://www.progresso.com.br/cotidiano/tuberculose-deixa-indios-mais-vulneraveisa-covid-19-em-dourados/371988/. Acesso em: 20 maio 2020.

BARATA, R. de C. B. Epidemias. Cadernos de Saúde Pública, Rio de Janeiro, v. 3, n. 1, p. 9-15, 1987. Disponível em: https://www.scielo.br/pdf/csp/v3n1/v3n1a02.pdf. Acesso em: 15 maio 2020.

BARRETO, M. L. Desigualdades em Saúde: uma perspectiva global. Ciências \& Saúde Coletiva, v. 22, n. 7, p. 2097-2108, jul. 2017. DOI: 10.1590/1413-81232017227.02742017. Disponível em: https://www.scielo.br/scielo.php?script=sci_arttext\&pid=S141381232017002702097\&lng=pt\&tlng=pt. Acesso em: 18 jul. 2020].

BARRY, J. M. A grande gripe: a história da gripe espanhola, a pandemia mais mortal de todos os tempos. 1. ed. Rio de Janeiro: Intrínseca, 2020. 
BENITES, E. Tekoha Ñeropu'ã: aldeia que se levanta. Revista NERA, v. 23, n. 52, p. 19-38. Dossiê. Presidente Prudente, mar. 2020. Disponível em:

https://revista.fct.unesp.br/index.php/nera/article/view/7187. Acesso em: 20 jun. 2020.

BOLETIM DSEI/MS. Boletim Coronavírus: casos COVID-19: Mato Grosso do Sul. Disponível em: https://www.saude.ms.gov.br/wp-content/uploads/2020/08/BOLETIMDSEI-MS-12.08.2020.pdf. Acesso em: 13 ago. 2020.

BRASIL. Ministério da Saúde. Gabinete do Ministro. Portaria N. ${ }^{\circ} 1163 / G M$, de 14 de setembro de 1999. Disponível em: http://www.funasa.gov.br/site/wpcontent/files_mf/Pm_1163_1999.pdf. Acesso em: 20 jul. 2020.

BRASIL. Ministério da Saúde. Protocolo de manejo clínico do Coronavírus (COVID-19) na atenção primária à saúde. 2020. Versão 8, BRASÍLIA: 2020. Disponível em: https://docs.bvsalud.org/biblioref/2020/04/1095396/20200422_protocolomanejo_vero 8.pdf. Acesso em: 25 jul. 2020.

BRASIL. Ministério da Saúde. Protocolo de Tratamento do Novo Coronavírus (2019nCoV). 2020. 31p. Disponível em: https://portalarquivos2.saude.gov.br/images/pdf/2020/fevereiro/05/Protocolo-demanejo-clinico-para-o-novo-coronavirus-2019-ncov.pdf. Acesso em: 18 jun. 2020.

BRASIL. Ministério da Saúde. Secretaria Especial de Saúde Indígena. Protocolo de acesso à Casa de Saúde do Índio do Distrito Federal. 2017. Brasília: Ministério da Saúde, 2017. Disponível em:

http://www.saude.gov.br/images/pdf/2017/fevereiro/08/Protocolo-de-acesso-CASAIDF.pdf. Acesso em: 25 jul. 2020.

BRASIL. Ministério da Saúde. Sistema Universidade Aberta do SUS. Atenção integral à saúde das populações do campo, da floresta e das águas. Fundação Oswaldo Cruz \& Universidade Federal de Mato Grosso do Sul. 2018. Disponível em: http://production.latec.ufms.br/modulos/pcfa201802/u1_2.html. Acesso em: 20 jun. 2020.

CONSELHO ESTADUAL DE EDUCAÇÃO DE MATO GROSSO DO SUL. Dispõe sobre a educação escolar indígena na educação básica do Sistema Estadual de Ensino de Mato Grosso do Sul. 2015. Disponível em: http://www.cee.ms.gov.br/wpcontent/uploads/2015/08/indica\%C3\%A7\%C3\%A30-n.-83-2015.pdf. Acesso em: 24 maio 2020.

CONSELHO INDIGENISTA MISSIONÁRIO. Nota do CIMI Regional Mato Grosso do Sul sobre a pandemia de covid-19 entre os Kaiowá e Guarani. 18 de maio 2020. Disponível em: https://cimi.org.br/2020/05/nota-do-cimi-ms-sobre-pandemia-covid-19-entrekaiowa-guarani/. Acesso em: 20 maio 2020.

DSEI/MATO GROSSO DO SUL. Caracterização do DSEI. 2017. Disponível em: https://portalarquivos2.saude.gov.br/images/pdf/2017/dezembro/o8/Anexo-1659355dsei-ms.pdf. Acesso em: 20 jul. 2020.

FUNDAÇÃO NACIONAL DE SAÚDE. Política Nacional de Atenção à Saúde dos Povos Indígenas. 2. ed. Brasília: Fundação Nacional de Saúde, 2002. Disponível em: http://bvsms.saude.gov.br/bvs/publicacoes/politica_saude_indigena.pdf. Acesso em: 20 jun. 2020. 
HAVERROTH, M. Experiências de pesquisa de campo em etnobiologia: relatos e reflexões. In: ARAÚJO, Thiago Antônio de Souza; ALBUQUERQUE, Ulysses Paulino de. Encontros e desencontros na pesquisa etnobiológica e etnoecológica: os desafios do trabalho em campo. Recife: NUPPEA, 2009. p.183-202.

INSTITUTO BRASILEIRO DE GEOGRAFIA E ESTATÍSTICA. Os indígenas no Censo Demográfico 2010 primeiras considerações com base no quesito cor ou raça. Rio de Janeiro: IBGE, 2102. Disponível em:

https://indigenas.ibge.gov.br/images/indigenas/estudos/indigena_censo2010.pdf. Acesso em: 18 jul. 2020.

JARDIM, C. Pandemias: o que são e como os países se comportam? [em linha]. 23 de abril 2020. Disponível em: https://www.politize.com.br/pandemias/. Acesso em: 24 maio 2020.

KRENAK, A. O amanhã não está à venda. São Paulo: Editora Schwarcz S. A. 2020. Ebook. Disponível em: https://www.amazon.com.br/amanh\%C3\%A3-n\%C3\%A30est\%C3\%A1-\%C3\%Ao-venda-ebook/dp/B0876HG28P. Acesso em: 24 maio 2020.

MACHADO, I. R. Coronavirus: Índia denuncia falta de água e comida em Dourados na ONU Mulheres (entrevista). O Progresso Digital, Dourados, abr. 2020a. Disponível em: https://www.progresso.com.br/cotidiano/coronavirus-india-denuncia-falta-de-agua-ecomida-em-dourados-na-onu/371673/. Acesso em: jul. 2020.

MACHADO, I. R. Para conter coronavírus, lideranças indígenas fecham acesso às aldeias (entrevista): Midiamax, Dourados, 23 de mar. 2020b. Disponível em: https://www.radiojotafm.com.br/noticias/para-conter-coronavirus-liderancasindigenas-fecham-acesso-as-aldeias/13664/. Acesso em: 25 jul. 2020.

MOURA, A. S. Endemias e epidemias: dengue, leishmaniose, febre amarela, influenza, febre maculosa e leptospirose. Belo Horizonte: Nescon/UFMG, 2012. E-book. Disponível em: https://www.nescon.medicina.ufmg.br/biblioteca/imagem/3285.pdf. Acesso em: 8 maio 2020.

PAGLIARO, H.; AZEVEDO, M. M.; SANTOS, R. V. (Org.). Demografia dos Povos Indígenas no Brasil: um panorama crítico. In: Demografia dos povos indígenas no Brasil. Rio de Janeiro: Editora Fiocruz: Associação Brasileira de Estudos Populacionais/Abep, 2005. p.11-32. E-book. Disponível em: http://books.scielo.org/id/qdgqt/pdf/pagliaro9788575412541.pdf. Acesso em: 20 jun. 2020.

PEREIRA, L. M. A Reserva indígena de Dourados: a atuação do Estado brasileiro e o surgimento de figurações indígenas multiétnicas. In: CHAMORRO, G.; COMBÈS, I. Povos indígenas em Mato Grosso do Sul: história, cultura e transformações sociais. Dourados, MS: Ed. UFGD, p.781-794. E-book. Disponível em: http://files.ufgd.edu.br/arquivos/arquivos/78/EDITORA/catalogo/povos_indigenas_em _mato_grosso_do_sul.pdf. Acesso em: 8 maio 2020.

PERFIL TERRITORIAL. Caderno territorial 035 Com Sul. Maio 2015. Disponível em: http://sit.mda.gov.br/download/caderno/caderno_territorial_035_Cone\%20Sul\%20\%20MS.pdf. Acesso em: 12 abr. 2020. 
SANTOS, B. de S. A cruel pedagogia do vírus. Lisboa: Biblioteca Nacional de Portugal, 2020. E-book. Disponível em: https://www.cpalsocial.org/documentos/927.pdf. Acesso em: 20 jun. 2020.

SCHATZMAYR, H. G.; CABRAL, M. C. A virologia no Estado do Rio de Janeiro: uma visão global. 2. ed. Rio de Janeiro: FIOCRUZ, 2012. E-book. Disponível em:

http://www.fiocruz.br/ioc/media/Livro_Virologia_nova_edicao.pdf. Acesso em: 20 jun. 2020.

SOUSA, N. M. O novo Coronavírus e os povos indígenas. 2020. Disponível em: https://www.academia.edu/42882335/O_NOVO_CORONA_V\%C3\%8DRUS_E_OS_POVO S_IND\%C3\%8DGENAS. Acesso em: 28 jun. 2020.

TERENA, D. Falta de água afeta 30 famílias na Aldeia Bananal, em Aquidauana, há 30 dias. Gazeta Trabalhista, Dourados, 28 abr. 2020. Disponível em: https://gazetatrabalhista.com.br/falta-de-agua-afeta-30-familias-na-aldeia-bananalem-aquidauana/. Acesso em: 28 jun. 2020. 